\title{
Work Stress and Satisfaction with Leadership Among Nurses Encountering Patient Aggression in Psychiatric Care: A Cross-Sectional Survey Study
}

\author{
Virve Pekurinen ${ }^{1}\left[\right.$ D $\cdot$ Maritta Välimäki ${ }^{1,2} \cdot$ Marianna Virtanen $^{3} \cdot$ Mika Kivimäki $^{4,5} \cdot$ Jussi Vahtera $^{6,7}$
}

Published online: 25 January 2019

(c) The Author(s) 2019

\begin{abstract}
We examined the associations between work stress (job strain, effort-reward imbalance), perceived job insecurity, workplace social capital, satisfaction with leadership and working hours in relation to the likelihood of encountering patient aggression (overall exposure, assaults on ward property, mental abuse, physical assaults). We conducted a cross-sectional survey for nurses $(\mathrm{N}=923)$ in 84 psychiatric units. Both work stress indicators were associated higher odds for different types of patient aggression. Poorer satisfaction with leadership was associated with higher odds for overall exposure to patient aggression. These findings were robust to adjustment for several nurse and work characteristics, and unit size.
\end{abstract}

Keywords Patient violence $\cdot$ Psychosocial work environment $\cdot$ Psychiatric nursing

\section{Introduction}

Patient aggression is common in psychiatric settings (Edward et al. 2016). Traditionally, patient aggression has been explained by patient characteristics such as having a severe mental disorder, a history of aggressive behavior or substance abuse (Dack et al. 2013). At the same time, a number of other factors may also contribute to patient aggression (Cutcliffe and Riahi 2013). Some factors are related to staff, such as young age (Camerino et al. 2008; Flannery et al. 2011), low qualification and little work experience (Flannery

Virve Pekurinen

vimapek@utu.fi

1 Department of Nursing Science, University of Turku, 20014 Turku, Finland

2 School of Nursing, Hong Kong Polytechnic University, Hong Kong, China

3 Department of Public Health and Caring Sciences, Uppsala University, Uppsala, Sweden

4 Clinicum, Faculty of Medicine, University of Helsinki, Helsinki, Finland

5 Finnish Institute of Occupational Health, Helsinki, Finland

6 Department of Public Health, University of Turku, Turku, Finland

7 Turku University Hospital, Turku, Finland et al. 2011). Nurses' gender (Camerino et al. 2008; Edward et al. 2016), and whether the work is full-time (Lepping et al. 2013) or in shifts (Camerino et al. 2008) have been found to be related to experiencing aggression.

Problems in psychosocial work environments may contribute to the occurrence of patient aggression (Shields and Wilkins 2009; Magnavita 2014). These include, for example, a lack of social support, interpersonal conflict, poor relationships with superiors, job insecurity, low participation in decision making, a lack of control over one's work, work overload and long working hours (Cox et al. 2009). Studies outside psychiatric settings have already linked poor social support at the workplace (Shields and Wilkins 2009), as well as problems with interpersonal relationships (Camerino et al. 2008), teamwork (Estryn-Behar et al. 2008) and superiors (Shields and Wilkins 2009), with increased aggression. Work stress, as indicated e.g., by a low level of job control in combination with high level of job demands (Karasek and Theorell 1990), has also been associated with patient aggression (Magnavita 2013, 2014).

Although several studies have reported associations between problems in the psychosocial work environment of healthcare staff and patient aggression (Camerino et al. 2008; Shields and Wilkins 2009; Magnavita 2013, 2014), research focusing on the topic in psychiatric settings is scarce. Earlier findings show that poor organizational justice (Pekurinen et al. 2017a) and poor collaboration between 
nurses (Bowers et al. 2009; Pekurinen et al. 2017a) may be linked with patient aggression. However, there is a lack of knowledge on how multiple factors in the psychosocial work environment are associated with patient aggression in psychiatric settings. The topic is important because of the individual (Needham et al. 2005) and economic burdens (Rubio-Valera et al. 2015) associated with patient aggression. Therefore, in this study, we examine the associations between work stress, perceived job insecurity, workplace social capital, satisfaction with leadership and working hours in relation to the likelihood of patient aggression. To our knowledge, this is the first study where the two leading stress models, the job strain model (Karasek and Theorell 1990) and the effort-reward imbalance (ERI) model (Siegrist 1996), have been empirically tested in relation to occurrence of patient aggression in psychiatric settings.

\section{Methods}

\section{Procedure and Participants}

Participants were selected from the psychiatric units in the Finnish Public Sector (FPS) Study (see Virtanen et al. 2011; Pekurinen et al. 2017b). Since 2000, employers' records have been used every fourth year to identify the employees who are eligible for questionnaire surveys. For this study, we used cross-sectional survey data from the years 2011-2012. The questionnaire was sent to all eligible nurses $(\mathrm{N}=1033)$ qualified as a practical or registered nurse who were working on one of the study units. First, questionnaires were sent by email, and three reminder emails were sent within 1 week of each other. Second, a paper version of the questionnaire was sent to the workplace of those who did not answer the emailed questionnaires. A total of 923 nurses responded to the survey ( $89 \%$ response rate). The Ethical Committee of the Helsinki and Uusimaa Hospital District assessed the study $(60 / 13 / 03 / 00 / 2011)$.

\section{Setting}

This study was conducted in all 84 psychiatric units situated in five hospital districts providing different types of specialized psychiatric care in Finland. In Finland, specialized healthcare is mostly public, and provided by 21 hospital districts (Ministry of Social Affairs and Health 2018). In $2015,169,631$ patients were treated in psychiatric services. Most patients are diagnosed with mood disorders (35\%, ICD-10: F30-39), followed by schizophrenia (14\%, ICD-10: F20-29: schizophrenia, schizotypal and delusional disorders) (National Institute of Health and Welfare 2017). The nursepatient ratio in Finland was among the highest in the OECD countries, with more than 14 nurses per 1000 population (year 2013, The Organisation for Economic Co-operation and Development 2015). In mental healthcare, the rate of nurses was 56.95 per 100,000 population in 2014 (World Health Organization 2014).

\section{Measures}

\section{Occurrence of Patient Aggression}

Occurrence of patient aggression was surveyed retrospectively. Nurses were asked to identify any of aggressive incidences in their job during last 12 months $(1=$ yes, $0=$ no; assaults on ward property [throwing or breaking objects], mental abuse [verbal threats], physical violence [hits or kicks], or armed threats [with firearm or edged weapon]) (Virtanen et al. 2011). To reflect the occurrence of physical assaults, we combined two aggression types, armed threats and physical assaults (Virtanen et al. 2011; Pekurinen et al. 2017b). We also created an indicator of overall exposure to patient aggression by combining the different types of aggression (assaults on ward property, mental abuse and physical assaults), where those who reported encountering any of the different types of aggression were coded as having experiences of patient aggression (Pekurinen et al. 2017b).

\section{Psychosocial Work Characteristics}

Effort-reward imbalance (ERI) was assessed in the same manner as in our earlier studies (Kivimäki et al. 2007): four survey questions adapted from the standard 10-item ERI scale developed by Siegrist (1996). For details of the four survey questions of our measure and the standard 10-item ERI scale, please see a study published by Juvani et al. (2014) (Appendix A, http://www.sjweh.fi/data_repos itory.php). The four items assess effort at work (1 item) and rewards (3 items; salary, esteem, promotion prospects) on a five-point scale $(1=$ very little $-5=$ very much). ERI was calculated in the standard way; as ratio of the effort and reward scales divided into tertiles (high, intermediate and low effort-reward imbalance) (Virtanen et al. 2009). The reward scale has demonstrated acceptable internal consistency ( $\alpha=0.64$, Juvani et al. 2014). The four-item proxy scale has a relatively high correlation $(\mathrm{R}=0.6)$ with the 10 -item ERI scale (Juvani et al. 2014).

Job strain was assessed with 12 items derived from the Job Content Questionnaire (JCQ, Karasek and Theorell 1990; for details see; Laine et al. 2009). Job strain is defined as a combination of two components: high job demands and low job control. Job demands refers to quantitative workload, and job control refers to the degree to which an employee can decide on the amount, tempo and method of his/her work (task decision authority) and opportunities for variable work in which the employee can use his/her 
competencies and learn new things (skills discretion) (Karasek and Theorell 1990). Job demand (3 items, derived from the original JCQs' psychological demand scale) and job control (9 items, derived from the original JCQs' decision latitude scale) were measured with a five-point scale $(1=$ disagree $-5=$ agree $)$. Details on the original JCQ items and our measure are reported elsewhere (Magnusson Hanson et al. 2018; Supplementary Table 2). We calculated job demand and job control using the mean response scores of individual questions. Job strain was defined as having a job with high demands (a mean score above study specific median) and low control (a mean score below the study specific median); no job strain was defined to be all other combinations of job demand and job control (Nyberg et al. 2014). The scale has demonstrated good internal consistency (job demands $\alpha=0.87$, job control $\alpha=0.80$, Karhula et al. 2013) and has demonstrated high correlation with the original version of the measure (Fransson et al. 2012).

Participation in decision making was measured with one item. The respondents were asked to rate the possibility of their participation in the planning of changes in their job with three possible scores: (1) changes are often unexpected, without the possibility to influence them, i.e., "low control", (2) I have the possibility to influence changes to some extent, i.e., "intermediate control" and (3) I can influence the changes to a great extent, i.e.,-_"high control" (Kivimäki et al. 2000).

Perceived job insecurity (Kivimäki et al. 2000) was measured with four items asking whether the respondent's job includes insecurity threats such as (1) being given notice, (2) being laid off, (3) being made redundant, and (4) being transferred to another job (1 very little -5 very much). The mean score of the items was divided into tertiles (high, intermediate and low job insecurity). The scale has previously demonstrated acceptable internal consistency $(\alpha=0.78$, Heponiemi et al. 2010).

Workplace social capital was assessed with an 8-item measure specifically designed for the purpose (Kouvonen et al. 2006). Social capital refers to social cohesion, trust, reciprocity, and cooperation in the workplace (Putnam 2000). The items included, e.g., "We have a 'we are together' attitude," "People feel understood and accepted by each other," "People in the work unit cooperate in order to help develop and apply new ideas," and "Our supervisor treats us with kindness and consideration" (five-point scale $1-5)$. We divided the mean response scores of the individual questions into tertiles (high, moderate and low social capital). This measure has demonstrated strong internal consistency ( $\alpha=0.88$, Oksanen et al. 2013).

Satisfaction with leadership was assessed with three relevant items derived from the Job Diagnostic survey (Hackman and Oldham 1975). The respondents were asked to rate their satisfaction with various aspects of leadership: (1) the amount of support and guidance received from the supervisor, (2) the degree of respect and fair treatment received from the boss and (3) the overall quality of supervision received at work ( 1 very unsatisfied -7 very satisfied). The mean score of the items was divided into tertiles (good, average and poor satisfaction with leadership) (Virtanen et al. 2009). These items have demonstrated excellent internal consistency ( $\alpha=0.93$, Virtanen et al. 2009).

Average working time was asked about to indicate hours on a daily basis. Mean working hours per day were calculated using a dichotomous variable: less than $9 \mathrm{~h}$ or more than $9 \mathrm{~h}$. Full-time employees in Finnish hospitals generally work $114.75 \mathrm{~h} / 3$ weeks $(7.65 \mathrm{~h} /$ days $)$. The daily working time is not allowed to exceed $10 \mathrm{~h}$, with the exception of night shifts in psychiatric care (maximum of $11 \mathrm{~h}$ ) (Municipal Collective Agreement 2010). However, we used $9 \mathrm{~h}$ as a cut-off point because, in Finnish hospitals, nurses usually work for approximately $8 \mathrm{~h}$ per shift, and appropriate shortening of working time is realized on specific days during the 3-week working period. Therefore, regularly working more than $9 \mathrm{~h}$ straight was considered to be overtime work.

Work unit size was indicated by the number of survey respondents in the unit.

\section{Characteristics of Nurses and Their Work}

The following demographic information was collected: age, sex, occupation (practical nurse, registered nurse/specialized nurse, ward/head nurse), nature of work (full-time, parttime), regular form of working hours (day work, shift work without nights, shift work with nights, night work, other irregular work) and duration of employment (number of years working at the current position). The nurses' negative affectivity, i.e., the tendency to answer questionnaires negatively, was assessed with the six-item Anxiety-Trait Scale, a short version of the 20-item State-Trait Anxiety Inventory (Spielberger et al. 1983). The respondents were asked to indicate how statements ("I feel calm," "I am relaxed," "I feel satisfied," "I feel tense," "I feel upset" and "I am worried") describe them in general $(1=$ not at all $-4=$ very much so). The mean score of the items was divided into tertiles (high, intermediate and low anxiety) (Saltychev et al. 2012). This was dichotomized as high anxiety vs. low and intermediate anxiety. This scale has demonstrated excellent internal consistency ( $\alpha=0.84$, Nabi et al. 2013).

\section{Statistical Analysis}

We analyzed the relationship between the covariates (nurse and work characteristics, and unit size) and patient aggression (overall exposure, assaults on ward property, mental abuse and physical assaults) with logistic regression analysis at the individual level. Because the participants were nested 
within 84 units, we used generalized linear mixed modeling (GLMM) to study the associations between psychosocial work characteristics and different types of patient aggression. This method takes into account the non-independence of observations within work units. We also counted the variance components (random effects) of patient aggression to estimate the unit-level variance in the prevalence. We report the random effects for the unit-level for empty models, models including covariates only and models including psychosocial work characteristics with covariates. The variance components differed significantly from zero $(\mathrm{p}<0.001)$, which supports the use of GLMM estimation. The statistical significance of interactions between psychosocial work characteristics and nurses' age, sex, nature of work, professional status, duration of employment and form of working hours (shift work vs. regular day work) were tested by including the corresponding interaction terms in the models. We found significant interactions between participation in decision making and nurses' age and professional status, and effort-reward imbalance and form of regular working hours (both $\mathrm{p}=0.03$ ) on patient aggression. Therefore, we also conducted a multilevel analysis examining the relationships between participation in decision making and patient aggression separately for different professional groups (practical nurses, and registered nurses together with head nurses). Relationships between effort-reward imbalance and patient aggression for shift workers and day workers were also analyzed separately.

To check for multicollinearity, we calculated the correlations between the covariates and psychosocial work characteristics. We allowed variables with $\mathrm{r}_{\mathrm{s}}<0.5$ in the same models. To ensure full adjustment, the adjustment was made for all nurse and work characteristics and unit size. The results are presented as odd ratios (ORs) and their $95 \%$ confidence intervals (CIs), with p values. SPSS 24 program package was used for analysis.

\section{Results}

\section{Descriptive Statistics}

Demographic information, trait anxiety and experiences of patient aggression of the participants are presented in Table 1.

\section{Covariates Associated with Patient Aggression}

Table 2 presents the results of the analysis of associations between covariates (nurse and work characteristics and unit size) with the different types of patient aggression. Nurses' age, sex, form of regular working hours and duration of employment were related to patient aggression.
Table 1 Demographic information, trait anxiety and experiences of patient aggression of the participants (see also Pekurinen et al. 2017b)

\begin{tabular}{|c|c|c|c|c|}
\hline & $\mathrm{N}$ & $\%$ & M & $\mathrm{SD}$ \\
\hline Age & - & - & 43.98 & 10.86 \\
\hline \multicolumn{5}{|l|}{ Sex } \\
\hline Female & 689 & 75 & - & - \\
\hline Male & 234 & 25 & - & - \\
\hline \multicolumn{5}{|l|}{ Nature of work } \\
\hline Full-time job & 877 & 95 & - & - \\
\hline Part-time job & 43 & 5 & - & - \\
\hline \multicolumn{5}{|l|}{ Professional status } \\
\hline Registered nurse & 539 & 59 & - & - \\
\hline Practical nurse & 289 & 31 & & \\
\hline Head nurse & 95 & 10 & - & - \\
\hline \multicolumn{5}{|l|}{ Form of working hours } \\
\hline Day shift & 296 & 32 & & \\
\hline Two shift & 141 & 15 & & \\
\hline Three shift & 442 & 48 & & \\
\hline Night shift & 33 & 4 & & \\
\hline Other irregular & 10 & 1 & & \\
\hline \multicolumn{5}{|l|}{ Duration of employment } \\
\hline Years in current position & - & - & 8.28 & 8.73 \\
\hline \multicolumn{5}{|l|}{ Trait anxiety } \\
\hline High & 347 & 38 & - & - \\
\hline Low & 576 & 62 & - & - \\
\hline \multicolumn{5}{|l|}{ Patient aggression } \\
\hline \multicolumn{5}{|l|}{ Overall exposure } \\
\hline Yes & 563 & 65 & - & - \\
\hline No & 297 & 35 & - & - \\
\hline \multicolumn{5}{|l|}{ Assaults on ward property } \\
\hline Yes & 440 & 49 & - & - \\
\hline No & 463 & 51 & - & - \\
\hline \multicolumn{5}{|l|}{ Mental abuse } \\
\hline Yes & 544 & 61 & - & - \\
\hline No & 343 & 39 & - & - \\
\hline \multicolumn{5}{|l|}{ Physical assaults } \\
\hline Yes & 333 & 38 & - & - \\
\hline No & 541 & 62 & - & - \\
\hline
\end{tabular}

\section{Psychosocial Work Characteristics Associated with Different Types of Patient Aggression}

Table 3 shows the results from a multilevel analysis examining the relationships between psychosocial work characteristics and patient aggression. Some psychosocial work characteristics were significantly related to the different types of patient aggression after controlling for nurse and work characteristics and work unit size. The work stress indicator, job strain, was associated with higher odds for assaults on ward property (OR 1.65, $\mathrm{p}=0.02$ ). Furthermore, its separate 


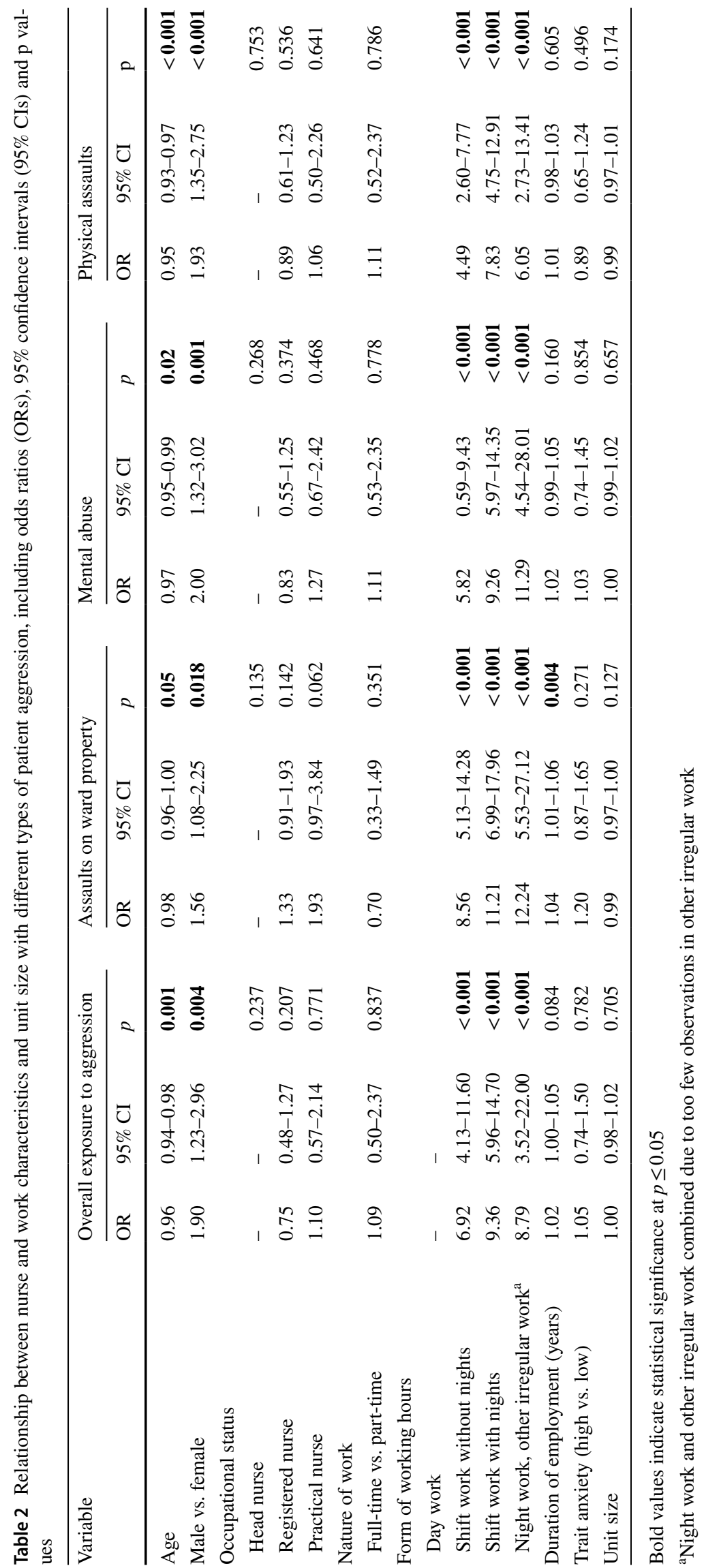


Table 3 Relationships between psychosocial work characteristics and different types of patient aggression including odds ratios (ORs) and 95\% confidence intervals (95\% CIs) for models including all participants

\begin{tabular}{|c|c|c|c|c|c|c|c|c|c|c|c|c|}
\hline \multirow[t]{2}{*}{ Psychosocial characteristic } & \multicolumn{3}{|c|}{ Overall exposure to aggression } & \multicolumn{3}{|c|}{ Assaults on ward property } & \multicolumn{3}{|c|}{ Mental abuse } & \multicolumn{3}{|c|}{ Physical assaults } \\
\hline & OR & $95 \% \mathrm{CI}$ & $p$ & OR & $95 \% \mathrm{CI}$ & $p$ & OR & $95 \% \mathrm{CI}$ & $p$ & OR & $95 \% \mathrm{CI}$ & $\mathrm{p}$ \\
\hline \multicolumn{13}{|l|}{ Job strain } \\
\hline Yes vs. no & 1.07 & $0.67-1.72$ & 0.764 & 1.65 & $1.07-2.54$ & 0.023 & 1.22 & $0.79-1.91$ & 0.370 & 1.50 & $0.97-2.33$ & 0.071 \\
\hline \multicolumn{13}{|l|}{ Job demands } \\
\hline High vs. low & 1.42 & $0.94-2.15$ & 0.097 & 1.99 & $1.34-2.95$ & 0.001 & 1.75 & $1.18-2.61$ & 0.006 & 1.48 & $0.99-2.21$ & 0.055 \\
\hline \multicolumn{13}{|l|}{ Job control } \\
\hline Low vs. high & 0.82 & $0.54-1.25$ & 0.363 & 1.03 & $0.70-1.50$ & 0.885 & 0.89 & $0.60-1.32$ & 0.577 & 1.13 & $0.76-1.69$ & 0.556 \\
\hline \multicolumn{13}{|c|}{ Participation in decision making } \\
\hline Low & 0.80 & $0.38-1.69$ & 0.561 & 0.84 & $0.39-1.79$ & 0.647 & 0.95 & $0.46-1.95$ & 0.879 & 0.80 & $0.35-1.81$ & 0.594 \\
\hline Intermediate & 0.90 & $0.48-1.90$ & 0.903 & 0.84 & $0.42-1.70$ & 0.631 & 1.08 & $0.56-2.1$ & 0.810 & 0.89 & $0.42-1.93$ & 0.786 \\
\hline High & Ref & & & Ref & & & Ref & & & Ref & & \\
\hline \multicolumn{13}{|l|}{ Effort-reward imbalance } \\
\hline High & 1.00 & $0.60-1.69$ & 0.988 & 1.62 & $0.99-2.63$ & 0.052 & 1.15 & $0.71-1.89$ & 0.569 & 1.50 & $0.89-2.51$ & 0.125 \\
\hline Intermediate & 0.79 & $0.50-1.25$ & 0.313 & 1.26 & $0.83-1.90$ & 0.279 & 0.91 & $0.59-1.40$ & 0.662 & 0.86 & $0.55-1.33$ & 0.492 \\
\hline Low & Ref & & & Ref & & & Ref & & & Ref & & \\
\hline \multicolumn{13}{|l|}{ Job insecurity } \\
\hline High & 0.84 & $0.52-1.35$ & 0.477 & 0.72 & $0.46-1.12$ & 0.142 & 0.89 & $0.57-1.41$ & 0.625 & 0.80 & $0.50-1.29$ & 0.365 \\
\hline Moderate & 1.22 & $0.74-2.00$ & 0.435 & 0.80 & $0.51-1.26$ & 0.799 & 1.29 & $0.81-2.05$ & 0.292 & 0.86 & $0.53-1.38$ & 0.525 \\
\hline Low & ref & & & ref & & & ref & & & ref & & \\
\hline \multicolumn{13}{|l|}{ Social capital } \\
\hline Low & 0.83 & $0.49-1.39$ & 0.472 & 0.91 & $0.56-1.47$ & 0.690 & 1.04 & $0.64-1.75$ & 0.864 & 0.77 & $0.46-1.29$ & 0.321 \\
\hline Intermediate & 1.10 & $0.67-1.80$ & 0.722 & 0.96 & $0.61-1.52$ & 0.866 & 1.18 & $0.73-1.89$ & 0.500 & 0.84 & $0.52-1.36$ & 0.485 \\
\hline High & ref & & & ref & & & ref & & & ref & & \\
\hline \multicolumn{13}{|l|}{ Satisfaction with leadership } \\
\hline Poor & 1.83 & $1.03-3.24$ & 0.040 & 1.32 & $0.77-2.27$ & 0.309 & 1.56 & $0.91-2.69$ & 0.108 & 1.22 & $0.69-2.17$ & 0.494 \\
\hline Average & 1.93 & $1.12-3.34$ & 0.019 & 0.99 & $0.60-1.65$ & 0.990 & 1.58 & $0.94-2.64$ & 0.084 & 1.29 & $0.75-2.15$ & 0.359 \\
\hline Good & ref & & & ref & & & ref & & & ref & & \\
\hline \multicolumn{13}{|l|}{ Work hours (daily) } \\
\hline$<9 \mathrm{~h} v s>9 \mathrm{~h}$ & 1.12 & $0.62-2.03$ & 0.714 & 1.04 & $0.59-1.84$ & 0.899 & 1.38 & $0.77-2.46$ & 0.277 & 0.81 & $0.45-1.48$ & 0.494 \\
\hline
\end{tabular}

Bold values indicate statistical significance at $p \leq 0.05$

A separate analysis was made for each psychosocial work characteristic

General linear mixed models adjusted for age, sex, occupation, nature of work, form of working hours, duration of employment, unit size and trait anxiety

component, high job demands, was related to higher odds for assaults on ward property and mental abuse (OR 1.99, $\mathrm{p}=0.001$, OR $1.75, \mathrm{p}=0.006$, respectively). We also found significant associations between poor and average satisfaction with leadership, and higher odds for overall exposure to patient aggression (OR 1.83, $\mathrm{p}=0.04$, OR 1.93, $\mathrm{p}=0.02$, respectively) (Table 3).

We also conducted an analysis examining the relationships between participation in decision making and different types of patient aggression separately for different professional groups (practical nurses $[n=289]$ and registered and head nurses $[n=634]$ ). We did not find any significant associations regarding participation in decision making and patient aggression in these different professional groups (data not shown). Relationships between effort-reward imbalance and different types of patient aggression for shift workers and day workers were also analyzed separately (shift workers $n=626$, day workers $n=296$ ). The analysis showed that among shift workers, a high effort-reward imbalance was associated with higher odds for assaults on ward property (OR 2.04, 95\% CI 1.13-3.66, $\mathrm{p}=0.02)$, whereas no significant associations were found among dayworkers (data not shown).

Table 4 shows the random effects (variance components) of the different types of patient aggression for the work unit level for empty models, the models including covariates and models including psychosocial work characteristics (for models including all participants). In each of the models, the variance components differed significantly from zero $(\mathrm{p}<0.001)$. The work unit variance of physical assaults 


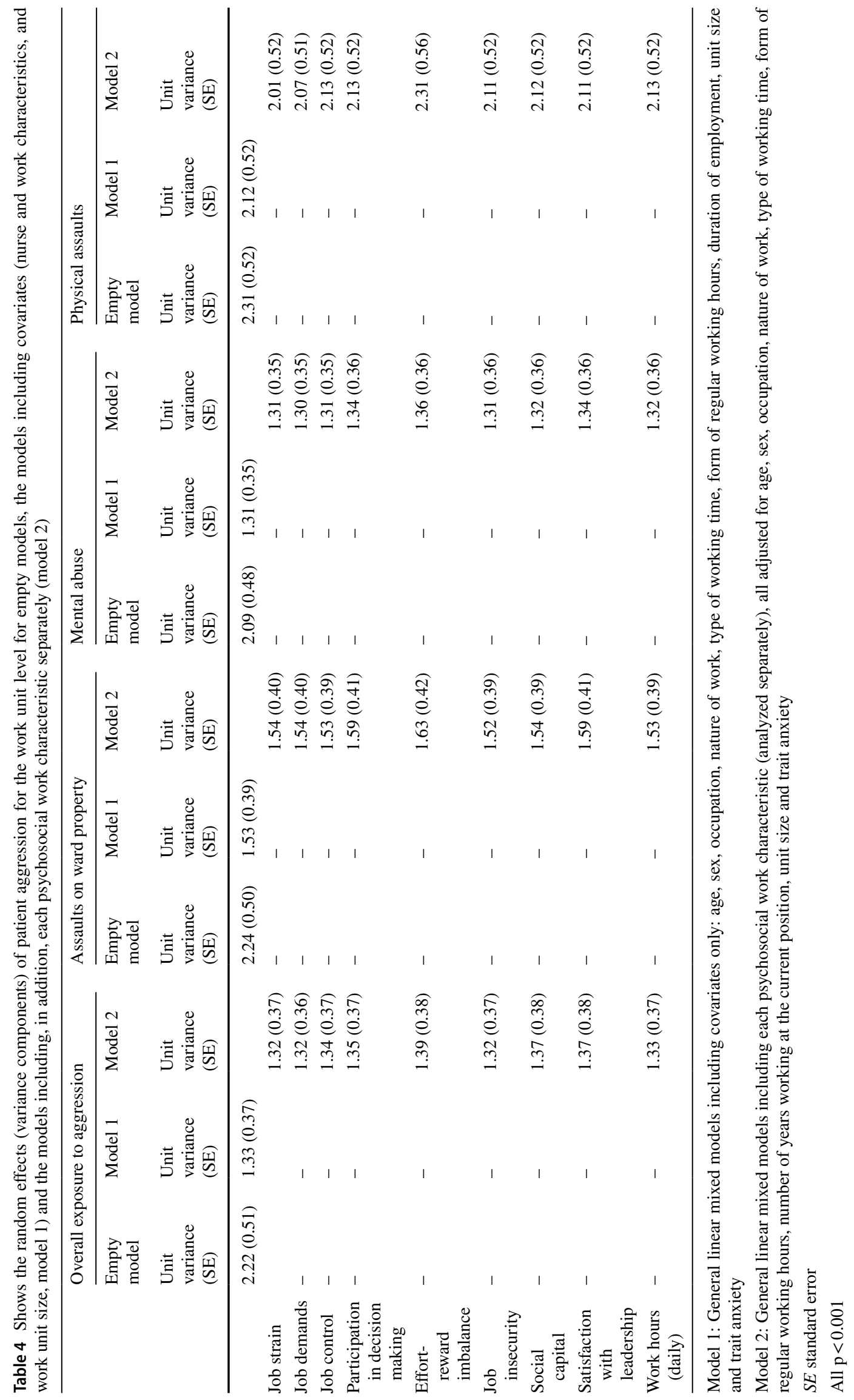


decreased by $8 \%$ after including the covariates in the models, while work unit variances of other types of patient aggression decreased by $32-40 \%$. When the psychosocial work characteristics were included in the models with the covariates, the work unit variance of patient aggression did not decrease notably (Table 4).

\section{Discussion}

In this cross-sectional multilevel study, nurses' work stress and satisfaction with leadership were associated with occurrence of patient aggression. Work stress as indicated by job strain and high job demands was associated with higher odds for occurrence of patient aggression for all nurses, while high effort-reward imbalance at work was associated with patient aggression for shift workers only. Both poor and average satisfaction with leadership were associated with higher odds for occurrence of patient aggression compared to the association between high satisfaction with leadership.

Studies conducted outside of the psychiatric setting on the association between job strain and workplace aggression have been published (Magnavita 2013, 2014; Park et al. 2015), and our results are consistent with the findings from those studies. The findings of our study as well as those of previous investigations may be explained by the effect of the high level of job strain on nurses' cognition (Elfering et al. 2011; Vuori et al. 2014). Task stressors (e.g., time pressure and frequent interruptions) foster cognitive failure in nurses, especially in attention regulation, but also action exertion (Elfering et al. 2011). Consequently, these difficulties might lead to, e.g., nurses neglecting early signs of aggression in patients or nurses being distracted at work-This is supported by the results of a qualitative study where psychiatric nurses described that patient aggression might be increased as a result of distractions in patient care caused by work pressure (Ward 2013). However, previous research suggests that the relationship between patient aggression and job strain might be cyclical; employees experiencing job strain are at a high risk of experiencing patient aggression, and on the other hand, the victims of aggression are at risk of job strain (Magnavita 2014). To find out if this is the case in psychiatric settings as well, more studies are needed.

Our study indicates that, among shift workers, work stress, in terms of a high effort-reward imbalance at work, is associated with higher odds for assaults on ward property by patients in psychiatric care. Although previous studies show that a high effort-reward imbalance among healthcare staff is linked with care quality indicators (Virtanen et al. 2009; Paquet et al. 2013), this is the first study, according to our knowledge, where an association between high effortreward imbalance and increased patient aggression has been found. Several possible explanations exist for our results.
The model of effort-reward imbalance claims that failed reciprocity, in terms of high efforts spent and low rewards received in turn, is likely to elicit recurrent negative emotions (Siegrist 1996). This failed reciprocity may result in poor commitment to aggression prevention practices through lowered work motivation, thus explaining the higher odds for patient aggression. On the other hand, another possible mechanism linking these factors might be risky behavior among nurses; the association between high effort-reward imbalance and risky behavior, in terms of, e.g., errors and deliberate driving violations, has already been observed among bus drivers (Useche et al. 2017). These factors may be linked when it comes to nurses as well-risky behavior among nurses might be related to, e.g., aggression prevention practices or interaction with patients, thus contributing to the increased occurrence of patient aggression. More studies are needed to determine if this is indeed the case.

The association between effort-reward imbalance and patient aggression was significant only among shift workers. We have no clear explanation for this. However, we already know that effort-reward imbalance is associated with rotating shift work (Lin et al. 2015). Furthermore, we may assume that the nature of work is different among these two groups; those who are working in shifts might be mainly working in different types of inpatient units as staff nurses, whereas those who are working regular day shifts are either working in outpatient care, or are head nurses. In inpatient units, patients' illnesses are often in the acute phase, and aggression is more common than in outpatient units. Consequently, if nurses' adherence to aggression prevention practices is lowered by means of a high effort-reward imbalance, or their interaction with patients is negatively affected by a high effort-reward imbalance, it can more easily be seen in the occurrence of patient aggression in inpatient units, rather than in, for example, outpatient units. However, this idea should be further investigated through studies conducted in these different types of settings separately.

Our study indicates that poor and average satisfaction with leadership is associated with higher odds for nurses' experiences of patient aggression. Our results are consistent with previous investigations (Estryn-Behar et al. 2008; Shields and Willkins 2009). Several possible explanations exist for our results and the results of previous studies. One possible mechanism linking leadership factors and patient aggression is that problems in leadership have been associated with problems in teamwork (Almost et al. 2010), which have been associated, in turn, with patient aggression (Camerino et al. 2008). Moreover, another possible mechanism linking these factors is the negative impact of poor leadership on nurses' behavior, not only towards colleagues (Priesemuth et al. 2013), but possibly patients as well. Problems in staff-patient interaction, possibly caused by poor leadership, may be associated with increased 
patient assaults (Papadopoulos et al. 2012). Encountering patient aggression is also an important source of stress and may be seen as failure of the management to effectively address the issue.

It should be taken into consideration that our data was collected over 5 years ago. Since 2012, some practice and policy changes have occurred that could affect the results if we were to conduct an identical study today. For example, from 2012 to 2015, industrial safety authorities conducted a monitoring project in the municipal sector related to occupational safety and health, which had an emphasis on social and healthcare providers and educational institutions. In the project, special attention was given to safety management, and the commitment of the management personnel to promoting safety was emphasized (Ministry of Social Affairs and Health 2014). Furthermore, the Finnish National Working Life Development Strategy to 2020 states, for example, the following focus areas, constructed based on assessment of Finnish working life in 2012: increasing the opportunity of personnel to influence their own work, management of excessive workloads and risks, making it more likely for employees to perceive work as rewarding and meaningful, and enhancing supervisor and colleague support for work tasks (Ministry of Employment and the Economy 2012).

The findings should be considered in the context of its limitations and strengths. We relied on nurses recalling patient aggression from the previous 12 months, which may have resulted in a recall bias (i.e., the underestimation or overestimation of the experiences of aggression due to recalling difficulties). This is especially the case because of the relatively long recall time used in our study. This may have distorted the measures of association, concerning their magnitude and/or direction, between the psychosocial work characteristics and aggression (Althubaiti 2016). We are not aware of any validation studies regarding our recall time for aggression, although evidence for shorter periods of time exist (Gerolamo 2008). Furthermore, underestimation of the exposure to aggression in particular is likely, regardless of whether indirect data collection (such as organizational incident reports) or direct data collection (such as self-reports) is used (Iennaco et al. 2013).

Unfortunately, we did not have any information on important risk factors for patient aggression, such as certain patient characteristics (see e.g., Dack et al. 2013) or unit size. However, in our analysis we included all available nurse characteristics that have previously been linked with increased exposure to patient aggression as covariates. To try to overcome the limitation regarding the lack of knowledge of unit sizes, we included it in the analysis as a by proxy measure.

Furthermore, although self-report measures have several limitations (see, e.g., Fowler 2009), all of our psychosocial work characteristics measures have been used previously with Finnish personnel (see, e.g., Virtanen et al. 2009; Karhula et al. 2013; Heponiemi et al. 2010; Oksanen et al. 2013). However, some of our measures were adapted from the original versions of the scales, indicating that our measures may have unknown psychometric properties. For example, we did not have data available collected with the standard 10-item ERI scale. A previous study found a moderate correlation between our scale and the original ERI scale (Juvani et al. 2014). It is possible, that the operationalization of the effort dimension of the effort-reward imbalance model with one item is not sufficient, and therefore the construct validity of our measure, together with the internal validity of our study, is weakened. The reward scale used in our study has demonstrated only acceptable internal consistency ( $\alpha=0.64$; Juvani et al. 2014), which may also indicate that not all the respondents understood the questions in the same way. Regarding our measure of satisfaction with leadership (three items derived from the items of Job Diagnostic Survey), although we know that it has demonstrated high internal consistency (Virtanen et al. 2009), we have no information on the successfulness of this operationalization in terms of, e.g., validity. Further, we used a single-item measure to investigate nurses' participation in decision making. Therefore, the respondents were left with ambiguity to interpret the meaning of the item. Because of the single-item nature, there was no possibility to compute internal consistency statistics to find out whether the respondents had understood the question similarly, and therefore, we have no information on the internal consistency reliability of the measure. Furthermore, single item scales do not cover a broad range of the construct under investigation, like multiple item scales do, which raises questions on the construct validity of this measure as well (Hoeppner et al. 2011).

In our study, we reached an excellent response rate (89\%). The explanation for this may be three-fold; first, the organizations are highly committed to the FPS study, because organizations are given reports on their results and development after each survey. Therefore, organizations are able to use the survey results to develop employees' wellbeing and thus benefit from participation. Second, we used reminders to increase response rates to the emailed survey (McPeake et al. 2014). Third, we sent paper questionnaires to those who did not answer the emailed questionnaires. The combination of emailed and mailed survey methods have been found to increase response rates in previous research as well (Kroth et al. 2009). On the other hand, we did not conduct non-response analysis of the characteristics of respondents and non-respondents, and therefore, we have no information of the possible non-response bias in our study. In a previous study conducted in similar settings in Finland, the respondents included slightly fewer women and registered nurses compared to our study (Korhonen et al. 2010). This 
may indicate that these groups were over-represented in our sample. However, the average age is quite similar to those previously reported regarding psychiatric settings (Koivunen et al. 2015). It is also possible that those who have experienced the most serious problems in psychosocial work environments, or experienced aggression most often, were not motivated to participate in the study.

In our study, we used cross-sectional data and we evaluated psychosocial work characteristics based on nurses' current experiences, while patient aggression was assessed retrospectively. This indicates that we cannot draw conclusions about the causality between our study variables. This highlights the importance of assessing the impact of the psychosocial work environment on patient aggression in psychiatric settings by means of longitudinal research.

In conclusion, our results provide important insights into psychosocial work characteristics as correlates to patient aggression in psychiatric settings. Longitudinal research is needed to verify our findings regarding the association between job strain, effort-reward imbalance and satisfaction with leadership and patient aggression in psychiatric settings. Research conducted separately in the different types of psychiatric settings (e.g., inpatient and outpatient units, child/adolescent and adult psychiatric care) is called for to clarify which settings are most vulnerable to the increasing occurrence of patient aggression induced by problems in the psychosocial work environment. Furthermore, the mechanisms underlying the associations of problems in the psychosocial work environment and patient aggression remain unknown, which needs to be addressed in future research.

Acknowledgements Open access funding provided by University of Turku (UTU) including Turku University Central Hospital. We also would like to thank Jaana Pentti, BSc for preparing the data for analysis, statistician Jouko Katajisto, MSc for helping with the data analysis and Leigh Ann Lindholm, MA for language editing.

Funding This study has been partially funded by the Finnish Work Environment Fund (111298, "Safer working management," 20122013), the Academy of Finland (projects 294298, 307367), and supported by the Doctoral Programme in Nursing Science (DPNurs), University of Turku, Finland. The data collection was conducted by the Finnish Public Sector Study and supported by the Academy of Finland (projects 264944, 267727).

\section{Compliance with Ethical Standards}

Conflict of interest Virve Pekurinen, Maritta Välimäki, Marianna Virtanen, Mika Kivimäki and Jussi Vahtera declares that they have no conflict of interest.

Ethical approval All procedures performed were in accordance with the ethical standards of the institutional research committee (The Ethical Committee of the Helsinki and Uusimaa Hospital District assessed the study [60/13/03/00/2011]) and with the 1964 Helsinki declaration and its later amendments.
Informed consent Nurses' completed and returned questionnaires were considered as their informed consent (Medical Research Act 9.4.1999/488).

Open Access This article is distributed under the terms of the Creative Commons Attribution 4.0 International License (http://creativeco mmons.org/licenses/by/4.0/), which permits unrestricted use, distribution, and reproduction in any medium, provided you give appropriate credit to the original author(s) and the source, provide a link to the Creative Commons license, and indicate if changes were made.

\section{References}

Almost, J., Doran, D. M., McGillis Hall, L., \& Spence Laschinger, H. K. (2010). Antecedents and consequences of intra-group conflict among nurses. Journal of Nursing Management, 18(8), 981-992. https://doi.org/10.1111/j.1365-2834.2010.01154.x.

Althubaiti, A. (2016). Information bias in health research: Definition, pitfalls, and adjustment methods. Journal of Multidisciplinary Healthcare, 9, 211-217. https://doi.org/10.2147/JMDH.S104807.

Bowers, L., Allan, T., Simpson, A., Jones, J., Van Der Merwe, M., \& Jeffery, D. (2009). Identifying key factors associated with aggression on acute inpatient psychiatric wards. Issues in Mental Health Nursing, 30(4), 260-271. https://doi.org/10.1080/01612 840802710829.

Camerino, D., Estryn-Behar, M., Conway, P. M., van Der Heijden, B. I., \& Hasselhorn, H. M. (2008). Work-related factors and violence among nursing staff in the european NEXT study: A longitudinal cohort study. International Journal of Nursing Studies, 45(1), 35-50.

Cox, T., Karanika-Murray, M., Griffiths, A., Wong, Y. Y. V., \& Hardy, C. (2009). Developing the management standards approach within the context of common health problems in the workplace: A delphi study, health and safety executive research report RR687. Nottingham: HSE Books. Retrieved from http://nrl.northumbri a.ac.uk/12366/.

Cutcliffe, J. R., \& Riahi, S. (2013). Systemic perspective of violence and aggression in mental health care: Towards a more comprehensive understanding and conceptualization: Part 2. International Journal of Mental Health Nursing, 22(6), 568-578. https://doi. org/10.1111/inm.12028.

Dack, C., Ross, J., Papadopoulos, C., Stewart, D., \& Bowers, L. (2013). A review and meta-analysis of the patient factors associated with psychiatric in-patient aggression. Acta Psychiatrica Scandinavica, 127(4), 255-268. https://doi.org/10.1111/acps.12053.

Edward, K. L., Stephenson, J., Ousey, K., Lui, S., Warelow, P., \& Giandinoto, J. A. (2016). A systematic review and meta-analysis of factors that relate to aggression perpetrated against nurses by patients/relatives or staff. Journal of Clinical Nursing, 25(3-4), 289-299. https://doi.org/10.1111/jocn.13019.

Elfering, A., Grebner, S., \& Dudan, A. (2011). Job characteristics in nursing and cognitive failure at work. Safety and Health at Work, 2(2), 194-200. https://doi.org/10.5491/SHAW.2011.2.2.194.

Estryn-Behar, M., van der Heijden, B., Camerino, D., Fry, C., Le Nezet, O., \& Conway, P. M., NEXT Study group. (2008). Violence risks in nursing-results from the european 'NEXT' study. Occupational Medicine, 58(2), 107-114. https://doi.org/10.1093/occmed/kqm14 2.

Flannery, R. B., Jr., LeVitre, V., Rego, S., \& Walker, A. P. (2011). Characteristics of staff victims of psychiatric patient assaults: 20 -year analysis of the assaulted staff action program. The 
Psychiatric Quarterly, 82(1), 11-21. https://doi.org/10.1007/ s11126-010-9153-z.

Fowler, F. J. (2009). Types of error in surveys. In F. J. Fowler (Ed.), Applied social research methods: Survey research methods (4th edn., pp. 11-17). Thousand Oaks: SAGE. https://doi. org/10.4135/9781452230184.

Fransson, E., Nyberg, S. T., Heikkilä, K., et al. (2012). Comparison of alternative versions of the job demand-control scales in 17 European cohort studies: The IPD-Work consortium. BMC Public Health 12, 62.

Gerolamo, A. M. (2008). Measuring adverse outcomes in inpatient psychiatry: The reliability of nurse recall. Archives of Psychiatric Nursing, 22(2), 95-103.

Hackman, J. R., \& Oldham, G. R. (1975). Development of the job diagnostic survey. Journal of Applied Psychology, 60(2), 159-170. https://doi.org/10.1037/h0076546.

Heponiemi, T., Elovainio, M., Pentti, J., Virtanen, M., Westerlund, H., Virtanen, P., \& Vahtera, J. (2010). Association of contractual and subjective job insecurity with sickness presenteeism among public sector employees. Journal of Occupational and Environmental Medicine, 52(8), 830-835. https://doi.org/10.1097/JOM.0b013 e3181ec7e23.

Hoeppner, B. B., Kelly, J. F., Urbanoski, K. A., \& Slaymaker, V. (2011). Comparative utility of a single-item versus multiple-item measure of self-efficacy in predicting relapse among young adults. Journal of Substance Abuse Treatment, 41(3), 305-312.

Iennaco, J. D., Dixon, J., Whittemore, R., \& Bowers, L. (2013). Measurement and monitoring of health care worker aggression exposure. Online Journal of Issues in Nursing, 18(1), 3.

Juvani, A., Oksanen, T., Salo, P., Virtanen, M., Kivimaki, M., Pentti, J., \& Vahtera, J. (2014). Effort-reward imbalance as a risk factor for disability pension: The finnish public sector study. Scandinavian Journal of Work, Environment \& Health, 40(3), 266-277. https ://doi.org/10.5271/sjweh.3402.

Karasek, R., \& Theorell, T. (1990). Healthy work: Stress, productivity, and the reconstruction of working life. New York: Basic Books.

Karhula, K., Harma, M., Sallinen, M., Hublin, C., Virkkala, J., Kivimaki, M., \& Puttonen, S. (2013). Association of job strain with working hours, shift-dependent perceived workload, sleepiness and recovery. Ergonomics, 56(11), 1640-1651. https://doi. org/10.1080/00140139.2013.837514.

Kivimaki, M., Vahtera, J., Elovainio, M., Virtanen, M., \& Siegrist, J. (2007). Effort-reward imbalance, procedural injustice and relational injustice as psychosocial predictors of health: Complementary or redundant models? Occupational and Environmental Medicine, 64(10), 659-665.

Kivimaki, M., Vahtera, J., Pentti, J., \& Ferrie, J. E. (2000). Factors underlying the effect of organisational downsizing on health of employees: Longitudinal cohort study. BMJ, 320(7240), 971-975.

Koivunen, M., Anttila, M., Kuosmanen, L., Katajisto, J., \& Välimäki, M. (2015). Team climate and attitudes toward information and communication technology among nurses on acute psychiatric wards. Informatics for Health and Social Care, 40(1), 79-90.

Korhonen, T., Vehviläinen-Julkunen, K., \& Pietilä, A. M. (2010). Do nurses support the patient in his or her role as a parent in adult psychiatry? A survey of mental health nurses in Finland. Archives of Psychiatric Nursing, 24(3), 155-167.

Kouvonen, A., Kivimaki, M., Vahtera, J., Oksanen, T., Elovainio, M., Cox, T., \& Wilkinson, R. G. (2006). Psychometric evaluation of a short measure of social capital at work. BMC Public Health. 6, 251.

Kroth, P. J., McPherson, L., Leverence, R., Pace, W., Daniels, E., Rhyne, R. L., \& Williams, R. L., Prime Net Consortium (2009). Combining web-based and mail surveys improves response rates:
A PBRN study from PRIME Net. The Annals of Family Medicine, 7(3), 245-248

Laine, S., Gimeno, D., Virtanen, M., Oksanen, T., Vahtera, J., Elovainio, M., \& Kivimaki, M. (2009). Job strain as a predictor of disability pension: The finnish public sector study. Journal of Epidemiology and Community Health, 63(1), 24-30. https://doi. org/10.1136/jech.2007.071407.

Lepping, P., Lanka, S. V., Turner, J., Stanaway, S. E., \& Krishna, M. (2013). Percentage prevalence of patient and visitor violence against staff in high-risk UK medical wards. Clinical Medicine, 13(6), 543-546. https://doi.org/10.7861/clinmedicine.13-6-543.

Lin, P. C., Chen, C. H., Pan, S. M., Chen, Y. M., Pan, C. H., Hung, H. C., \& Wu, M. T. (2015). The association between rotating shift work and increased occupational stress in nurses. Journal of Occupational Health, 57(4), 307-315. https://doi.org/10.1539/ joh.13-0284-OA.

Magnavita, N. (2013). The exploding spark: Workplace violence in an infectious disease hospital-a longitudinal study. BioMed Research International, 2013, 316358. https://doi. org/10.1155/2013/316358.

Magnavita, N. (2014). Workplace violence and occupational stress in healthcare workers: A chicken-and-egg situation-results of a 6-year follow-up study. Journal of Nursing Scholarship: An Official Publication of Sigma Theta Tau International Honor Society of Nursing, 46(5), 366-376. https://doi.org/10.1111/jnu.12088.

Magnusson Hanson, L. L., Westerlund, H., Chungkham, H. S., Vahtera, J., Rod, N. H., Alexanderson, K., Goldberg, M., Kivimäki, M., Stenholm, S., Platts, L. G., Zins, M., \& Head, J. (2018). Job strain and loss of healthy life years between ages 50 and 75 by sex and occupational position: Analyses of 64934 individuals from four prospective cohort studies. Occupational and Environmental Medicine, 75(7), 486-493.

McPeake, J., Bateson, M., \& O'Neill, A. (2014). Electronic surveys: How to maximise success. Nurse Researcher, 21(3), 24-26.

Ministry of Social Affairs and Health (2014). Threat of violence in the working life-Reports of committee on threat of violence section. https://julkaisut.valtioneuvosto.fi/bitstream/handle/10024 174694/RAP2014_17_v\%C3\%A4kivallan_uhka.pdf?sequence=1. [original in Finnish: Väkivallan uhka työelämässä - Työturvallisuussäännöksiä valmisteleva neuvottelukunta Väkivallan uhkajaoston raportti].

Ministry of Social Affairs and Health Finland. (2018). Hospitals and specialised medical care. Retrieved from http://stm.fi/en/hospi tals-and-specialised-medical-care.

Ministry of the Employment and the Economy (2012). National working life development strategy to 2020. http://www.tyoelama20 20.fi/files/104/Strategy_2020.pdf.

Municipal Collective Agreement 2010-2011. (2010). Retrieved from https://ao453-tehy-fi-bin.directo.fi/@Bin/b37cccb4403ba762debd fa5b98f8d6d4/1522749118/application/pdf/193099/KVTES _2010-2011.pdf [Original in Finnish: KVTES 2010-2011. Kunnallinen yleinenvirka- ja työehtosopimus].

Nabi, H., Virtanen, M., Singh-Manoux, A., Hagger-Johnson, G., Pentti, J., Kivimaki, M., \& Vahtera, J. (2013). Trait anxiety levels before and after antidepressant treatment: A 3-wave cohort study. Journal of Clinical Psychopharmacology, 33(3), 371-377. https://doi. org/10.1097/JCP.0b013e31828b26c2.

National Institute of Health and Welfare. (2017). Psychiatric specialised health care 2015. Statistical report. 21/2017. Retrived from https://www.julkari.fi/bitstream/handle/10024/134729/Tr21_17. pdf? sequence $=1$.

Needham, I., Abderhalden, C., Halfens, R. J., Fischer, J. E., \& Dassen, T. (2005). Non-somatic effects of patient aggression on nurses: A systematic review. Journal of Advanced Nursing, 49(3), 283-296. 
Nyberg, S. T., Fransson, E. I., Heikkila, K., Ahola, K., Alfredsson, L., \& Bjorner, J. B., IPD-Work Consortium (2014). Job strain as a risk factor for type 2 diabetes: A pooled analysis of 124,808 men and women. Diabetes Care, 37(8), 2268-2275. https://doi. org/10.2337/dc13-2936.

Oksanen, T., Kawachi, I., Kouvonen, A., Takao, S., Suzuki, E., Virtanen, M., \& Vahtera, J. (2013). Workplace determinants of social capital: Cross-sectional and longitudinal evidence from a finnish cohort study. PLoS One, 8(6), e65846. https://doi.org/10.1371/ journal.pone.0065846.

Papadopoulos, C., Ross, J., Stewart, D., Dack, C., James, K., \& Bowers, L. (2012). The antecedents of violence and aggression within psychiatric in-patient settings. Acta Psychiatrica Scandinavica, 125(6), 425-439. https://doi.org/10.1111/j.1600-0447.2012.01827 .x.

Paquet, M., Courcy, F., Lavoie-Tremblay, M., Gagnon, S., \& Maillet, S. (2013). Psychosocial work environment and prediction of quality of care indicators in one canadian health center. Worldviews on Evidence-Based Nursing, 10(2), 82-94. https://doi.org/10.11 11/j.1741-6787.2012.00250.x.

Park, M., Cho, S. H., \& Hong, H. J. (2015). Prevalence and perpetrators of workplace violence by nursing unit and the relationship between violence and the perceived work environment. Journal of Nursing Scholarship: An Official Publication of Sigma Theta Tau International Honor Society of Nursing, 47(1), 87-95. https ://doi.org/10.1111/jnu.12112.

Pekurinen, V., Willman, L., Virtanen, M., Kivimaki, M., Vahtera, J., \& Valimaki, M. (2017b). Patient aggression and the wellbeing of nurses: A cross-sectional survey study in psychiatric and non-psychiatric settings. International Journal of Environmental Research and Public Health. https://doi.org/10.3390/ijerph14101245.

Pekurinen, V. M., Valimaki, M., Virtanen, M., Salo, P., Kivimaki, M., \& Vahtera, J. (2017a). Organizational justice and collaboration among nurses as correlates of violent assaults by patients in psychiatric care. Psychiatric Services, 68(5), 490-496. https://doi. org/10.1176/appi.ps.201600171.

Priesemuth, M., Arnaud, A., \& Schminke, M. (2013). Bad behavior in groups. Group \& Organization Management, 38(2), 230-257. https://doi.org/10.1177/1059601113479399.

Putnam, R. D. (2000). Bowling alone: The collapse and revival of American community. New York: Simon \& Schuster.

Rubio-Valera, M., Luciano, J. V., Ortiz, J. M., Salvador-Carulla, L., Gracia, A., \& Serrano-Blanco, A. (2015). Health service use and costs associated with aggressiveness or agitation and containment in adult psychiatric care: A systematic review of the evidence. BMC Psychiatry. https://doi.org/10.1186/s12888-015-0417-x.
Saltychev, M., Laimi, K., Oksanen, T., Pentti, J., Virtanen, M., Kivimaki, M., \& Vahtera, J. (2012). Effect of a multidisciplinary rehabilitation programme on perceived health among employees at increased risk of incapacity for work: A controlled study. Clinical Rehabilitation, 26(6), 513-522. https://doi.org/10.1177/02692 15511425963.

Shields, M., \& Wilkins, K. (2009). Factors related to on-the-job abuse of nurses by patients. Health Reports, 20(2), 7-19.

Siegrist, J. (1996). Adverse health effects of high-effort/low-reward conditions. Journal of Occupational Health Psychology, 1(1), $27-41$.

Spielberger, C. D., Gorsuch, R. L., Lushene, R., Vagg, P. R., \& Jacobs, G. A. (1983). Manual for the state-trait anxiety inventory. Palo Alto: Consulting Psychologists Press.

The Organisation for Economic Co-operation and Development. (2015). Health at a Glance 2015. Retrieved from https://www. health.gov.il/publicationsfiles/healthataglance2015.pdf.

Useche, S. A., Ortiz, V. G., \& Cendales, B. E. (2017). Stress-related psychosocial factors at work, fatigue, and risky driving behavior in bus rapid transport (BRT) drivers. Accident; Analysis and Prevention, 104, 106-114.

Virtanen, M., Kurvinen, T., Terho, K., Oksanen, T., Peltonen, R., Vahtera, J., \& Kivimaki, M. (2009). Work hours, work stress, and collaboration among ward staff in relation to risk of hospital-associated infection among patients. Medical Care, 47(3), 310-318. https://doi.org/10.1097/MLR.0b013e3181893c64.

Virtanen, M., Vahtera, J., Batty, G. D., Tuisku, K., Pentti, J., Oksanen, T., \& Kivimaki, M. (2011). Overcrowding in psychiatric wards and physical assaults on staff: Data-linked longitudinal study. The British Journal of Psychiatry: The Journal of Mental Science, 198(2), 149-155. https://doi.org/10.1192/bjp.bp.110.082388.

Vuori, M., Akila, R., Kalakoski, V., Pentti, J., Kivimaki, M., Vahtera, J., \& Puttonen, S. (2014). Association between exposure to work stressors and cognitive performance. Journal of Occupational and Environmental Medicine, 56(4), 354-360. https://doi.org/10.1097/ JOM.0000000000000129.

Ward, L. (2013). Ready, aim fire! mental health nurses under siege in acute inpatient facilities. Issues in Mental Health Nursing, 34(4), 281-287. https://doi.org/10.3109/01612840.2012.742603.

World Health Organization. (2014). Finland. Mental Health Atlas Country Profile 2014. Retrieved from http://www.who.int/menta 1_health/evidence/atlas/profiles-2014/en/.

Publisher's Note Springer Nature remains neutral with regard to jurisdictional claims in published maps and institutional affiliations. 